\title{
Contribuição dos componentes de rendimento na produtividade de genótipos crioulos de feijão (Phaseolus vulgaris L.) ${ }^{1}$
}

\author{
Contribution of the yield components to grain yield of common beans (Phaseolus \\ vulgaris $\mathrm{L}$.) landrace genotypes
}

\author{
Marcio Zilio ${ }^{2}$, Cileide Maria Medeiros Coelho ${ }^{3 *}$, Clovis Arruda Souza ${ }^{4}$, Julio Cesar Pires Santos ${ }^{5}$ e David José \\ Miquelluti ${ }^{6}$
}

\begin{abstract}
Resumo - Este trabalho teve por objetivo verificar a contribuição relativa dos componentes do rendimento para a produção final em genótipos de feijão (Phaseolus vulgaris L). O experimento foi conduzido com 26 genótipos de feijão na safra 2008/2009 nos municípios de Anchieta, Joaçaba e Lages, estado de Santa Catarina, sob delineamento experimental em blocos ao acaso com 3 repetições, onde avaliou-se os componentes do rendimento e produtividade. Foi utilizado o teste de variância univariada para determinação da variabilidade e da resposta dos genótipos aos diferentes ambientes de cultivo e os testes de Scott-Knott e Tukey para comparação das médias. As correlações foram estimadas através da análise de Trilha. Foi observada resposta diferenciada dos genótipos nos ambientes testados para todos os caracteres avaliados, com exceção da massa de 100 grãos. A seleção indireta para massa de 100 grãos para elevado rendimento de grãos não é uma boa estratégia para o progresso genético, devido aos efeitos indiretos negativos. Mas, a seleção para número de vagens por planta, número de grãos por vagem e número de lóculos por legume podem contribuir efetivamente para incrementar o rendimento de grãos.
\end{abstract}

Palavras-chave - Phaseolus vulgaris L. Rendimento de grãos. Componentes da produção. Características agronômicas. Análise de trilha.

\begin{abstract}
The objective this work was to verify the relative contribution between yield components and yield of the common bean landraces cultivars. The experiment was carried out with twenty six genotypes of beans under field conditions in the 2008/2009 growing season using randomized block design with three repetitions, where evaluated the yields components and yield in the in the following Santa Catarina countries: Anchieta, Joaçaba and Lages. The unvaried variance test was used and the cropping places were compared by Tukey test and, Scott-Knott test to grouping genotypes. The correlations were done by path analysis. The genotypes evaluated performed differently according to the environment where the tests were done to all characters, with exception to the mass of 100 grains. The indirect selection by mass of 100 grains to yield component isn't a good alternative to genetic progress. But, the selection to pod number per plant, grain per pod and pod loci number can contribute to yield selection.
\end{abstract}

Key words - Phaseolus vulgaris. Genotype. Environment. Landrace cultivar. Genetic resources. Stepwise.

\footnotetext{
* Autor para correspondência

${ }^{1}$ Recebido para publicação em 18/08/2010; aprovado em 19/02/2011

Parte da Dissertação de Mestrado do primeiro autor

${ }^{2}$ Programa de Pós-Graduação em Produção Vegetal, CAV/UDESC, Departamento de Agronomia, Lages-SC, Brasil, marciozilio@gmail.com

${ }^{3}$ Centro de Ciências Agrárias, Departamento de Fitotecnia/UFSC, Florianópolis-SC, Brasil, cileide@cca.ufsc.br

${ }^{4}$ Departamento de Agronomia, área de plantas de lavoura, CAV/DEAGRO/UDESC, Lages-SC, Brasil, souza_clovis@cav.udesc.br

${ }^{5}$ Departamento de Solos e Recursos Naturais, área de microbiologia, CAV/UDESC, Departamento de Agronomia, Lages-SC, Brasil, a2jcps@

cav.udesc.br

${ }^{6}$ Departamento de Solos e Recursos Naturais, área de estatística, Lages-SC, Brasil, a2djm@cav.udesc.br
} 


\section{Introdução}

A produção nacional de feijão (Feijão comumPhaseolus vulgaris e Feijão-caupi - Vigna unguiculata) registrada na safra 2009 foi 3.478 .775 t, provenientes de 4.129 .423 ha cultivados, com produtividade de $842,4 \mathrm{~kg} \mathrm{ha}^{-1}$ (IBGE, 2009). Em Santa Catarina a área colhida foi 89.500 ha, $14,5 \%$ maior que a do ano 2008 , porém, a produção obtida foi de 131.386 t. O rendimento foi $1.468 \mathrm{~kg} \mathrm{ha}^{-1}, 18,6 \%$ inferior ao do ano anterior.

$\mathrm{Na}$ cultura do feijão, a produtividade de grãos é altamente correlacionada com os componentes da produção: número de vagens por planta, número de grãos por planta e massa de grãos (COSTA; ZIMMERMANN, 1988). Dependendo das condições, alguns componentes da produção podem aumentar e outros diminuir, facilitando a manutenção da estabilidade produtiva (CASQUERO et al., 2006).

Os três principais caracteres que compõem o rendimento final na cultura do feijão são: número de vagens por unidade de área, número de grãos por vagem e massa dos grãos. O número de vagens por unidade de área é determinado pela população de plantas, pela produção de flores por planta e pelo número de flores que efetivamente desenvolvem vagens. Segundo Ramos Junior et al. (2005), o tamanho de grãos e o número de grãos por vagem são os componentes de maior influência na produtividade de grãos de feijão.

Os componentes do rendimento são determinados pelo genótipo, influenciados pelas condições ambientais ocorrentes durante o ciclo da cultura, pelas práticas fitotécnicas adotadas durante a implantação e condução da lavoura e pelo nível tecnológico adotado pelo agricultor (BEZERRA et al., 2007; KAPPES et al., 2008).

Poderá haver efeito compensatório no rendimento de grãos, com a diminuição do número de vagens e de grãos por planta de feijão e do aumento da massa dos grãos, em resposta ao aumento da população de plantas por área. Em feijão, o efeito compensatório nos componentes de rendimento, foi observado quando esta cultura foi submetida à densidade de plantas menores que a recomendada (SHIMADA et al., 2000). Em trabalho realizado por Kappes et al. (2008), a cultivar BRS-Valente apresentou a maior produtividade, mesmo tendo o menor número de sementes por vagem, em comparação ao BRSRequinte. Segundo Fageria et al. (2006), os componentes da produção não influenciam o rendimento final de grãos de forma independente, mas sim em conjunto.

A correlação de um caráter pode assumir um valor positivo, negativo ou igual a zero. Porém, Cruz e Regazzi (1994) relatam que a quantificação e a interpretação da magnitude de uma correlação pode resultar em equívocos na estratégia de seleção, pois correlação elevada pode ser resultado do efeito, sobre estes, de um terceiro ou de um grupo de caracteres. Neste contexto, a análise de trilha é um dos métodos para entender as causas envolvidas nas associações entre caracteres e decompor a correlação existente em efeitos diretos e indiretos, através de uma variável principal como o rendimento de grãos e as variáveis explicativas, ou seja, os componentes do rendimento.

Portanto, o objetivo deste trabalho foi verificar a contribuição relativa dos componentes do rendimento para a produção final em genótipos crioulos de feijão, cultivados em três ambientes.

\section{Material e métodos}

O experimento foi conduzido a campo com 26 genótipos, sendo 22 genótipos crioulos e 4 cultivares comerciais, pertencentes ao Banco Ativo de Feijão (BAF) da Universidade do Estado de Santa Catariana (UDESC). Os trabalhos foram realizados em três municípios de Santa Catarina (Lages, Joaçaba e Anchieta), na safra de 2008/2009.

Lages está localizada no Planalto Sul de Santa Catarina, com altitude média de $930 \mathrm{~m}$, verão brando, temperatura média de $15^{\circ} \mathrm{C}$ e precipitação anual de 1.500 $\mathrm{mm}$. Joaçaba situa-se no meio oeste catarinense, com altitude média de $522 \mathrm{~m}$, clima mesotérmico úmido, sem estação seca, verão quente, temperatura média anual de $18{ }^{\circ} \mathrm{C}$ e precipitação anual de $2.000 \mathrm{~mm}$. O município de Anchieta localiza-se no extremo oeste catarinense, com altitude média de $745 \mathrm{~m}$, clima mesotérmico úmido, verão quente, temperatura média de $17,8^{\circ} \mathrm{C}$ e precipitação anual de $1.700 \mathrm{~mm}$ (EPAGRI, 2010).

Os genótipos utilizados foram os BAFs: $3 ; 4 ; 7$; $13 ; 23 ; 36 ; 42 ; 44 ; 46 ; 47 ; 50 ; 55 ; 57 ; 60 ; 68 ; 75 ; 81$; $84 ; 97 ; 102 ; 108 ; 112 ; 115 ; 120 ; 121$ e 192 . As quatro cultivares comerciais foram: BAF 112 (IPR88-Uirapurú); BAF 115 (BRS-Valente); BAF 121 (Iapar 81) e BAF 192 (BRS-Radiante).

O delineamento experimental foi o de blocos completos casualizados, com três repetições, em parcelas de quatro linhas de três metros, com 15 sementes por metro, sendo as duas linhas externas consideradas como bordaduras e a área útil as duas linhas internas, excluindo 0,5 metros das extremidades. Foi utilizado o delineamento em blocos completos casualizados para evitar possível heterogeneidade dentro de cada área experimental, sendo os blocos arranjados no sentido perpendicular à declividade do terreno. A adubação de base foi realizada junto às linhas, previamente à semeadura, segundo análise 
do solo e recomendações descritas em publicações da Comissão de Química e Fertilidade do Solo - CQFSRS/SC (2004). A adubação de cobertura foi realizada duas vezes, nos estádios de três trifólios e no inicio da floração (V4 e R5), utilizando-se uma dosagem de $30 \mathrm{~kg}$ de $\mathrm{N}$ por hectare em cada aplicação. O controle de plantas daninhas, doenças e de pragas foi feito de acordo com as necessidades, utilizando-se os produtos químicos recomendados para a cultura.

Os genótipos foram avaliados após a colheita quanto à número médio de lóculos por vagem, comprimento da vagem, espessura da vagem, massa de 100 grãos, número de vagens por planta, número de grãos por vagem e produtividade de grãos.

A produtividade de grãos foi estimada em $\mathrm{kg} \mathrm{ha}^{-1}$, em razão do rendimento de grãos na área útil de cada parcela. Para a obtenção das características agronômicas foram coletadas ao acaso 10 plantas da área útil de cada parcela experimental (IPGRI, 2001). A massa de 100 grãos foi obtida de plantas da área útil da parcela. A porcentagem de grãos abortados foi feita através da equação: 100 x 1 - (número de grãos por vagem/número de lóculos por vagem).

Todas as variáveis estudadas foram submetidas à análise de variância univariada (STEEL et al., 1997) obedecendo a um modelo linear de efeitos fixos (LITTEL et al., 1991; LITTEL et al., 2006) para os três componentes, local, genótipo e a resposta do genótipo ao ambiente de cultivo. As comparações entre os valores médios, de cada uma das variáveis analisadas, nos diferentes genótipos em cada local de cultivo, foram efetuadas pelo teste de Scott-Knott e, entre os locais, para cada genótipo, pelo teste Tukey (SCOTT; KNOTT, 1974). O teste de Scott-Knott foi utilizado porque é um método de comparação múltipla baseado em análise de agrupamento univariada, que elimina a ambiguidade que ocorre entre dois genótipos, tido como diferentes entre si, mas que não diferem de um terceiro. O teste de Tukey é utilizado para comparação de médias baseado na diferença mínima significativa (DMS), com alto rigor de discriminação, o qual foi usado para comparar os ambientes. As associações entre os componentes do rendimento, ciclo, qualidade tecnológica, qualidade nutricional e produtividade, foram estimadas através da análise de trilha ou de caminhamento. Para todos os testes efetuados foi considerado o nível mínimo de significância de 5\% $(\mathrm{P}<0,05)$. Os caracteres avaliados foram o rendimento de grãos (variável básica) e os seus componentes primários (variáveis explicativas): número de grãos por vagem, número de vagens por planta, número de lóculos/vagem, massa de 100 grãos, comprimento da vagem e espessura da vagem. Como a relação entre as variáveis explicativas e a variável básica é estruturalmente multiplicativa, transformaramse os dados para a escala logarítmica, de modo que fosse obtida a determinação completa do modelo de regressão linear múltipla. Para a seleção de variáveis no modelo adotou-se o método passo a passo (stepwise) (CRUZ; REGAZZI, 1994; STEEL et al., 1997).

\section{Resultados e discussão}

Após análise dos dados (TAB. 1), verificouse resposta diferenciada dos genótipos aos ambientes de cultivo para a maioria dos caracteres avaliados, com exceção da massa de 100 grãos, possivelmente por ser um caráter de herança qualitativa, pouco influenciado pelo ambiente e controlado por poucos genes, conforme constatado por Ramalho et al. (1993). Também foi observada diferença significativa entre os genótipos para todos os caracteres avaliados, nos três locais. Estas respostas mostram a presença de variabilidade genética entre as cultivares e o efeito do ambiente de cultivo sobre cada genótipo para as avaliações realizadas. Portanto, existe a necessidade da avaliação de genótipos em diferentes locais, anos e épocas de semeadura, devido a ampla diversidade de condições ambientais em que o feijão é cultivado no Brasil (CARBONELL et al., 2007; COELHO et al., 2007; LEMOS et al., 2004; RIBEIRO et al., 2009), e particularmente devido a ampla diversidade genética observada nos genótipos crioulos de feijão (COELHO et al., 2007). Outras evidências da contribuição genética para os componentes de produção já foi observada com outros genótipos de feijão-caupi (ANDRADE et al., 2010). Bem como, a caracterização de diversidade através da pesquisa e manutenção de genótipos locais de feijão (BALKAYA; ERGÜN, 2008).

O teste de Scott-Knott foi utilizado, pois é um método de comparação múltipla baseado em análise de agrupamento univariada, que elimina a ambiguidade que ocorre entre dois genótipos, tido como diferentes entre si, mas que não diferem de um terceiro, e apresenta poderes semelhantes nas distribuições normais e não normais dos resíduos, robusto à violação de normalidade (SCOTT; KNOTT, 1974). Desta forma, observou-se que os BAFs: $03 ; 04 ; 13 ; 36 ; 44 ; 47 ; 50 ; 55 ; 68 ; 81 ; 97 ; 108 ; 115 ; 120$ e 121, não apresentaram diferença significativa entre os locais, quanto à produtividade (TAB. 2). Os demais genótipos apresentaram produtividades superiores em Joaçaba, com destaque para os BAFs: 42; 57; 102; 112 e 121, que em Joaçaba apresentaram produtividades médias acima de $4.000 \mathrm{~kg} \mathrm{ha}^{-1}$. Em Anchieta destacase o BAF 55 e em Lages o BAF 13, com produtividades médias acima de $3.000 \mathrm{~kg} \mathrm{ha}^{-1}$. Os genótipos cultivados 
Tabela 1 - Análises conjuntas de variância e valores de probabilidade (P) referentes à produtividade (PROD), número de vagens por planta (NVP), número de grãos por vagem (NGV), número de lóculos por vagem (NLV), massa de 100 grãos (MCG), comprimento da vagem (CV) e espessura de vagem (EV) de 26 genótipos de feijão do Banco Ativo de Feijão (BAF) da UDESC, cultivados em três municípios de Santa Catarina, na safra de 2008/2009

\begin{tabular}{|c|c|c|c|c|c|c|c|c|}
\hline \multirow[b]{2}{*}{ Causas de variação } & \multirow[b]{2}{*}{ G.L. } & \multicolumn{7}{|c|}{ Quadrado médio } \\
\hline & & PROD & NVP & $\mathrm{NGV}$ & NLV & MCG & $\mathrm{CV}$ & EV \\
\hline Ambiente (A) & 2 & $53.320,074^{*}$ & $9,406^{*}$ & $0,896^{*}$ & $0,610^{*}$ & $170,871^{*}$ & $19,087^{*}$ & $0,138^{*}$ \\
\hline Genótipo (G) & 25 & $1.976,811^{*}$ & $1,591^{*}$ & $0,141^{*}$ & $0,139^{*}$ & $590,609^{*}$ & $8,613 *$ & $0,044^{*}$ \\
\hline $\mathrm{G} \times \mathrm{A}$ & 50 & $619.843^{*}$ & $0,331 *$ & $0,015^{*}$ & $0,012 *$ & $7,834^{\mathrm{ns}}$ & $1,443^{*}$ & $0,022 *$ \\
\hline Bloco & 3 & $117.615^{\mathrm{ns}}$ & $0,103^{\text {ns }}$ & $0,005^{\mathrm{ns}}$ & $0,003^{\text {ns }}$ & $14,59^{\text {ns }}$ & $0,176^{\mathrm{ns}}$ & $0,002^{\mathrm{ns}}$ \\
\hline \multirow[t]{2}{*}{ Resíduo } & 75 & 247.274 & 0,079 & 0,004 & 0,002 & 8,192 & 0,557 & 0,004 \\
\hline & & \multicolumn{7}{|c|}{$\operatorname{Pr}>F$} \\
\hline \multicolumn{2}{|c|}{ Causas de variação } & PROD & NVP & NGV & NLV & $\mathrm{MCG}$ & $\mathrm{CV}$ & $\overline{\mathrm{EV}}$ \\
\hline \multicolumn{2}{|l|}{ Ambiente (A) } & 0,0002 & 0,0021 & 0,0008 & 0,0008 & 0,0383 & 0,0016 & 0,0038 \\
\hline \multicolumn{2}{|l|}{ Genótipo (G) } & $<0,0001$ & $<0,0001$ & $<0,0001$ & $<0,0001$ & $<0,0001$ & $<0,0001$ & $<0,0001$ \\
\hline \multicolumn{2}{|l|}{$\mathrm{G} \times \mathrm{A}$} & 0,0002 & $<0,0001$ & $<0,0001$ & $<0,0001$ & 0,5615 & $<0,0001$ & $<0,0001$ \\
\hline \multicolumn{2}{|l|}{ Bloco } & 0,7002 & 0,2814 & 0,3555 & 0,2636 & 0,1581 & 0,8130 & 0,6341 \\
\hline
\end{tabular}

* significativo a $\mathrm{P}<0,05$; ns não significativo a $\mathrm{P}<0,05$

em Joaçaba apresentaram maior produtividade média (3.478 $\mathrm{kg} \mathrm{ha}^{-1}$ ), seguido pelos genótipos conduzidos em Anchieta (1.783 $\left.\mathrm{kg} \mathrm{ha}^{-1}\right)$ e Lages $\left(1.671 \mathrm{~kg} \mathrm{ha}^{-1}\right)$ (TAB. 2).

Destacaram-se com produtividades acima da média nos três locais o BAF 13; BAF 42; BAF 50; BAF 55; BAF 81; BAF 102; BAF 112 BAF 115 e BAF 121, evidenciando um bom desempenho produtivo dos genótipos nos ambientes estudados. Os genótipos BAF 13; BAF 50; BAF 55; BAF 81 e BAF 121 apresentaram produtividades acima de $2.000 \mathrm{~kg} \mathrm{ha}^{-1}$ para os três locais de cultivo.

Em outros trabalhos têm sido demonstrado a existência de respostas diferenciadas dos genótipos a ambientes de cultivos na produtividade, ocorrendo diferenças no comportamento das cultivares em locais, enos anos agrícolas e nas épocas de semeadura (CARBONELL et al., 2004; ELIAS et al., 2007; RAMALHO et al., 1993; RIBEIRO et al., 2009). Também tem sido estudada a reação de genótipos crioulos em distintas zonas agroecológicas para cultivo de feijão na busca de se atender as necessidades da agricultura familiar, como por exemplo o caso na Malávia, África (MWALE et al., 2008). Mas ainda carente nestas informações no estado de Santa Catarina.

Com relação aos principais componentes do rendimento, em Anchieta, o BAF 23, BAF 108 e o BAF 84 apresentaram o maior número de vagens por planta (> 16 vagens). Em Joaçaba os BAFs que apresentaram o maior número de vagens por planta foi o $84 ; 121$;
$7 ; 60 ; 102$ e 42 (> 17 vagens). Em Lages foram os BAFs 36; 13 e 44 que apresentaram o maior número de vagens por planta ( $>13$ vagens). Os genótipos cultivados em Joaçaba apresentaram maior número de vagens por planta (14 vagens/planta), seguido pelos genótipos conduzidos em Anchieta (11 vagens/planta) e Lages (8 vagens/planta) (TAB. 2).

Em relação ao número de grãos por vagem, em Anchieta destacou-se os BAFs $112 ; 75 ; 13 ; 81 ; 55 ; 42$ e 36 (> 6 grãos/vagem). Em Joaçaba os genótipos que apresentaram o maior número grãos por vagem foram os BAFs $13 ; 75 ; 60 ; 115 ; 55 ; 121 ; 36 ; 112$ e 102 (> 6 grãos /vagem). E em Lages os BAFs 7; 13; 112; 60; 42 e 75 foram os que apresentaram o maior número de grãos por vagem (> 5 grãos/vagem). Os genótipos cultivados em Joaçaba e Anchieta apresentaram o maior número de grãos por vagem (5 grãos/vagem), seguido pelos genótipos conduzidos em Lages (4 grãos/vagem) (TAB. 3).

A massa de 100 grãos (MMG) foi a variável mais estável quando comparada nos três locais, na média de todos os genótipos, sendo o valor da MMG de 31,$9 ; 30,4$ e 28,4 g, respectivamente Lages, Joaçaba e Anchieta; diferença de apenas 3,6 $\mathrm{g}$ entre o ambiente de maior MMG (Lages) comparado ao de menor MMG (Anchieta). Em relação às diferenças entre as cultivares, pelo teste de agrupamento de médias homogêneas de Scott-Knott formaram-se nove grupos de cultivares conforme a MMG, com destaques para os BAFs 46; 47; 120 e 192 com valores acima 
Tabela 2 - Produtividade e número de legumes por planta de 26 genótipos de feijão do Banco Ativo de Feijão (BAF) da UDESC, cultivados em três municípios de Santa Catarina, na safra de 2008/2009

\begin{tabular}{|c|c|c|c|c|c|c|}
\hline \multirow{2}{*}{ Genótipo } & \multicolumn{3}{|c|}{ Produtividade $\left(\mathrm{kg} \mathrm{ha}^{-1}\right)$} & \multicolumn{3}{|c|}{ Número de vagens/planta } \\
\hline & Anchieta & Joaçaba & Lages & Anchieta & Joaçaba & Lages \\
\hline 03 & $1099,1 \mathrm{Ab}$ & $2616,7 \mathrm{Ab}$ & $1220,1 \mathrm{Aa}$ & $5,7 \mathrm{Ac}$ & $10,1 \mathrm{Ac}$ & $6,9 \mathrm{Ad}$ \\
\hline 04 & $841,5 \mathrm{Ab}$ & $2010,9 \mathrm{Ab}$ & $1656,1 \mathrm{Aa}$ & $6,0 \mathrm{Ac}$ & 9,9 Ac & 7,9 Ac \\
\hline 07 & $493,3 \mathrm{Bb}$ & $2776,0 \mathrm{Ab}$ & $1937,7 \mathrm{ABa}$ & $11,2 \mathrm{ABb}$ & $20,5 \mathrm{Aa}$ & $7,9 \mathrm{Bc}$ \\
\hline 13 & $2351,4 \mathrm{Aa}$ & $3768,2 \mathrm{Aa}$ & $3064,6 \mathrm{Aa}$ & $11,9 \mathrm{Ab}$ & $15,1 \mathrm{Ab}$ & $14,6 \mathrm{Aa}$ \\
\hline 23 & $925,5 \mathrm{ABb}$ & $2788,2 \mathrm{Ab}$ & $570,6 \mathrm{Ba}$ & $8,5 \mathrm{Ac}$ & $10,6 \mathrm{Ac}$ & $4,5 \mathrm{Ad}$ \\
\hline 36 & $2203,5 \mathrm{Aa}$ & $3327,0 \mathrm{Ab}$ & $1605,0 \mathrm{Aa}$ & $12,1 \mathrm{Ab}$ & $16,5 \mathrm{Ab}$ & $15,3 \mathrm{Aa}$ \\
\hline 42 & $1986,8 \mathrm{Ba}$ & $4451,9 \mathrm{Aa}$ & $2470,0 \mathrm{ABa}$ & $14,0 \mathrm{Ab}$ & $18,0 \mathrm{Aa}$ & $11,6 \mathrm{Ab}$ \\
\hline 44 & $1514,8 \mathrm{Ab}$ & $2282,3 \mathrm{Ab}$ & $1957,1 \mathrm{Aa}$ & $11,2 \mathrm{Ab}$ & $9,4 \mathrm{Ac}$ & $13,8 \mathrm{Aa}$ \\
\hline 46 & $1909,3 \mathrm{ABa}$ & $3723,8 \mathrm{Aa}$ & $1540,6 \mathrm{Ba}$ & $8,6 \mathrm{Ac}$ & $9,0 \mathrm{Ac}$ & $6,3 \mathrm{Ad}$ \\
\hline 47 & $2122,4 \mathrm{Aa}$ & $2661,1 \mathrm{Ab}$ & $1107,2 \mathrm{Aa}$ & 7,1 Ac & $9,2 \mathrm{Ac}$ & $4,6 \mathrm{Ad}$ \\
\hline 50 & $2298,6 \mathrm{Aa}$ & $3665,4 \mathrm{Aa}$ & $2646,1 \mathrm{Aa}$ & $10,3 \mathrm{Ab}$ & $10,7 \mathrm{Ac}$ & 7,9 Ac \\
\hline 55 & $3536,6 \mathrm{Aa}$ & $3766,5 \mathrm{Aa}$ & $1806,0 \mathrm{Aa}$ & $11,7 \mathrm{Ab}$ & $14,3 \mathrm{Ab}$ & $8,3 \mathrm{Ac}$ \\
\hline 57 & $1875,9 \mathrm{Ba}$ & $5096,1 \mathrm{Aa}$ & $491,8 \mathrm{Ba}$ & $6,9 \mathrm{AB}$ & $13,4 \mathrm{Ac}$ & $2,5 \mathrm{Be}$ \\
\hline 60 & $1544,7 \mathrm{Bb}$ & $3941,4 \mathrm{Aa}$ & $1713,8 \mathrm{Ba}$ & $14,5 \mathrm{Ab}$ & $19,7 \mathrm{Aa}$ & $5,2 \mathrm{Bd}$ \\
\hline 68 & $1183,6 \mathrm{Ab}$ & $2761,0 \mathrm{Ab}$ & $750,1 \mathrm{Aa}$ & $9,1 \mathrm{Abc}$ & $14,7 \mathrm{Ab}$ & $5,4 \mathrm{Bd}$ \\
\hline 75 & $2704,3 \mathrm{ABa}$ & $3955,9 \mathrm{Aa}$ & $1519,1 \mathrm{Ba}$ & $13,4 \mathrm{Ab}$ & $13,9 \mathrm{Ab}$ & $8,1 \mathrm{Ac}$ \\
\hline 81 & $2117,2 \mathrm{Aa}$ & $3693,0 \mathrm{Aa}$ & $2329,9 \mathrm{Aa}$ & $11,4 \mathrm{Ab}$ & $13,3 \mathrm{Ac}$ & $10,5 \mathrm{Ab}$ \\
\hline 84 & $2351,4 \mathrm{ABa}$ & $3948,7 \mathrm{Aa}$ & $1430,3 \mathrm{Ba}$ & $16,7 \mathrm{Aa}$ & $21,4 \mathrm{Aa}$ & $6,7 \mathrm{Bd}$ \\
\hline 97 & $1181,9 \mathrm{Ab}$ & $3103,7 \mathrm{Ab}$ & $1058,6 \mathrm{Aa}$ & $7,4 \mathrm{Ac}$ & $9,5 \mathrm{Ac}$ & $3,9 \mathrm{Ae}$ \\
\hline 102 & $1823,0 \mathrm{Ba}$ & $5018,1 \mathrm{Aa}$ & $2672,6 \mathrm{Ba}$ & $13,7 \mathrm{Ab}$ & $18,3 \mathrm{Aa}$ & $10,9 \mathrm{Ab}$ \\
\hline 108 & $1106,1 \mathrm{Ab}$ & $2750,5 \mathrm{Ab}$ & $1887,7 \mathrm{Aa}$ & 17,9 Aa & $13,0 \mathrm{Ac}$ & $11,0 \mathrm{Ab}$ \\
\hline 112 & $2306,8 \mathrm{ABa}$ & $4385,8 \mathrm{Aa}$ & $1931,1 \mathrm{Ba}$ & $12,5 \mathrm{Ab}$ & $13,2 \mathrm{Ac}$ & $11,5 \mathrm{Ab}$ \\
\hline 115 & $2601,5 \mathrm{Aa}$ & $3856,0 \mathrm{Aa}$ & $1871,0 \mathrm{Aa}$ & $20,6 \mathrm{Aa}$ & $12,7 \mathrm{Ac}$ & $10,8 \mathrm{Bb}$ \\
\hline 120 & $804,9 \mathrm{Ab}$ & $2822,5 \mathrm{Ab}$ & $981,5 \mathrm{Aa}$ & $4,4 \mathrm{Ac}$ & 7,0 Ac & 3,3 Ae \\
\hline 121 & $2080,2 \mathrm{Aa}$ & $4019,4 \mathrm{Aa}$ & $2524,1 \mathrm{Aa}$ & $13,8 \mathrm{Ab}$ & $21,0 \mathrm{Aa}$ & $12,3 \mathrm{Ab}$ \\
\hline 192 & $1398,3 \mathrm{ABb}$ & $3246,8 \mathrm{Ab}$ & $705,7 \mathrm{Ba}$ & $6,2 \mathrm{Abc}$ & $9,6 \mathrm{Ac}$ & $2,8 \mathrm{Be}$ \\
\hline
\end{tabular}

Médias seguidas de mesma letra maiúscula não diferiram significativamente entre os locais de cultivo (linha), pelo teste tukey a $5 \%$ de significância. Médias seguidas de mesma letra minúscula, não diferiram significativamente em cada local de cultivo (coluna), pelo teste de Scott-Knott a 5\% de significância

de $40 \mathrm{~g}$ (TAB. 3). No entanto, alguns genótipos apresentaram valores baixos da MMG, como o BAF 7 e BAF 84 (abaixo de $20 \mathrm{~g})$. Entre os 26 genótipos avaliados, 12 apresentaram MMG entre 20 e $26 \mathrm{~g}$ (grupo "g” e "h" - TAB. 3).

Através da análise de trilha (TAB. 4), observou-se que em Anchieta a produtividade apresentou correlação positiva com o número de grãos por vagem $(0,68)$, número de vagens por planta $(0,41)$ e número de lóculos por vagem $(0,53)$, indicando que incrementos nesses caracteres refletem positivamente na produtividade, e correlação negativa com a massa de 100 grãos $(-0,33)$, comprimento de vagem $(-0,14)$ e espessura de vagem $(-0,27)$, indicando que quanto maior o tamanho dos grãos, e o comprimento e espessura das vagens, menor foi a produtividade.

Em Joaçaba a produtividade apresentou correlação positiva com o número de vagens por planta $(0,40)$, número de grãos por vagem $(0,42)$ e com o número de lóculos por vagem $(0,53)$ e correlação negativa com a massa de 100 grãos (-0,33). A correlação entre comprimento $(-0,07)$ e espessura da vagem $(-0,03)$ evidenciou uma falta de associação com o rendimento de grãos.

Em Lages o número de vagens por planta $(0,68)$, número de grãos por vagem $(0,54)$ e número de lóculos 
Tabela 3 - Número de grãos por vagem e massa de 100 grãos, 26 genótipos de feijão do Banco Ativo de Feijão (BAF) da UDESC, cultivados em três municípios de Santa Catarina, na safra de 2008/2009

\begin{tabular}{|c|c|c|c|c|c|c|c|}
\hline \multirow{2}{*}{ Genótipo } & \multicolumn{3}{|c|}{ Número de grãos/vagem } & \multicolumn{3}{|c|}{ Massa de 100 grãos } & \multirow{2}{*}{ Média } \\
\hline & Anchieta & Joaçaba & Lages & Anchieta & Joaçaba & Lages & \\
\hline 3 & $4,8 \mathrm{Ac}$ & 4,6 $\mathrm{Aa}$ & $3,7 \mathrm{Ac}$ & 28,6 & 31,9 & 33,2 & $31,2 \mathrm{e}$ \\
\hline 4 & $3,7 \mathrm{Ad}$ & $3,9 \mathrm{Ac}$ & $3,5 \mathrm{Ac}$ & 35,4 & 38,1 & 41,5 & $38,3 \mathrm{~d}$ \\
\hline 7 & $5,0 \mathrm{Ac}$ & $5,7 \mathrm{Ab}$ & $5,8 \mathrm{Aa}$ & 16,4 & 21,3 & 21,0 & $19,6 \mathrm{i}$ \\
\hline 13 & $6,5 \mathrm{Aa}$ & 6,3 Ac & $5,8 \mathrm{Aa}$ & 22,3 & 22,8 & 26,3 & $23,8 \mathrm{~g}$ \\
\hline 23 & 4,9 Abc & $5,4 \mathrm{Ab}$ & $3,8 \mathrm{Bc}$ & 33,9 & 40,2 & 40,9 & $38,3 \mathrm{~d}$ \\
\hline 36 & $6,0 \mathrm{Aa}$ & 5,9 Aa & $3,9 \mathrm{Bc}$ & 21,4 & 23,5 & 25,3 & $23,4 \mathrm{~g}$ \\
\hline 42 & $6,3 \mathrm{Aa}$ & $5,3 \mathrm{Ab}$ & $5,0 \mathrm{Aa}$ & 19,1 & 19,4 & 24,5 & $21,0 \mathrm{~h}$ \\
\hline 44 & $5,4 \mathrm{Ab}$ & $5,2 \mathrm{Ab}$ & $4,4 \mathrm{Ab}$ & 23,5 & 26,3 & 24,7 & $24,8 \mathrm{~g}$ \\
\hline 46 & $5,3 \mathrm{Ab}$ & $5,0 \mathrm{Ac}$ & $3,6 \mathrm{Bc}$ & 39,7 & 40,9 & 41,4 & $40,7 \mathrm{c}$ \\
\hline 47 & $5,4 \mathrm{Ab}$ & $4,5 \mathrm{Ac}$ & $4,5 \mathrm{Ab}$ & 37,2 & 43,4 & 45,3 & $42,0 \mathrm{c}$ \\
\hline 50 & $5,7 \mathrm{Ab}$ & $5,5 \mathrm{Ab}$ & $4,5 \mathrm{Ab}$ & 24,1 & 26,4 & 30,1 & $26,9 \mathrm{f}$ \\
\hline 55 & $6,3 \mathrm{Aa}$ & $6,0 \mathrm{Aba}$ & $4,8 \mathrm{Bb}$ & 22,0 & 21,7 & 23,0 & $22,2 \mathrm{~h}$ \\
\hline 57 & $4,3 \mathrm{Ac}$ & $4,5 \mathrm{Ac}$ & $3,7 \mathrm{Ac}$ & 36,6 & 38,5 & 41,5 & $38,9 \mathrm{c}$ \\
\hline 60 & $5,3 \mathrm{Ab}$ & 6,2 Aa & $5,1 \mathrm{Aa}$ & 20,5 & 21,9 & 24,2 & $22,2 \mathrm{~h}$ \\
\hline 68 & 4,9 Ac & $4,5 \mathrm{Ac}$ & $3,7 \mathrm{Ac}$ & 32,2 & 35,8 & 41,3 & $36,4 \mathrm{~d}$ \\
\hline 75 & $6,5 \mathrm{Aa}$ & 6,2 Aba & $5,0 \mathrm{Ba}$ & 20,5 & 21,4 & 23,3 & $21,7 \mathrm{~h}$ \\
\hline 81 & $6,4 \mathrm{Aa}$ & 5,5 Abb & $4,4 \mathrm{Bb}$ & 19,1 & 20,3 & 22,1 & $20,5 \mathrm{~h}$ \\
\hline 84 & $5,7 \mathrm{Ab}$ & $5,5 \mathrm{Ab}$ & $4,9 \mathrm{Ab}$ & 19,8 & 20,4 & 18,6 & $19,6 \mathrm{i}$ \\
\hline 97 & $4,6 \mathrm{Ac}$ & $4,7 \mathrm{Ac}$ & $4,1 \mathrm{Ac}$ & 32,8 & 38,8 & 41,6 & $37,7 \mathrm{~d}$ \\
\hline 102 & $5,5 \mathrm{AB}$ & $5,8 \mathrm{Aa}$ & $4,5 \mathrm{Bb}$ & 24,8 & 25,8 & 24,1 & $24,9 \mathrm{~g}$ \\
\hline 108 & $5,2 \mathrm{Ab}$ & $4,8 \mathrm{Ac}$ & $4,3 \mathrm{Ab}$ & 21,1 & 25,8 & 27,7 & $24,9 \mathrm{~g}$ \\
\hline 112 & 6,6 Aa & 5,9 Aa & 5,3 Aa & 23,8 & 25,3 & 28,9 & $26,0 \mathrm{~g}$ \\
\hline 115 & $5,8 \mathrm{Ab}$ & 6,1 Aa & $4,1 \mathrm{Bc}$ & 23,6 & 24,6 & 27,3 & $25,2 \mathrm{~g}$ \\
\hline 120 & 3,8 Abd & $4,4 \mathrm{Ac}$ & $3,1 \mathrm{Bc}$ & 50,7 & 52,6 & 45,6 & $49,6 \mathrm{~b}$ \\
\hline 121 & 5,3 Abb & 5,9 Aa & $4,3 \mathrm{Bb}$ & 27,6 & 26,8 & 30,0 & $28,1 \mathrm{f}$ \\
\hline 192 & $4,5 \mathrm{Ac}$ & $4,8 \mathrm{Ac}$ & $3,2 \mathrm{Bc}$ & 58,6 & 55,4 & 55,7 & $56,6 \mathrm{a}$ \\
\hline Média & - & - & - & $28,3 \mathrm{C}$ & $30,4 \mathrm{~B}$ & $31,9 \mathrm{~A}$ & \\
\hline
\end{tabular}

Médias seguidas de mesma letra maiúscula não diferiram significativamente entre os locais de cultivo, pelo teste tukey a 5\% de significância. Médias seguidas de mesma letra minúscula, não diferiram significativamente em cada local de cultivo, pelo teste de Scott-Knott a 5\% de significância

por vagem $(0,50)$ apresentaram correlação positiva com a produtividade, enquanto que a massa de 100 grãos $(-0,53)$ e a espessura da vagem $(-0,31)$ apresentaram correlação negativa e o comprimento da vagem $(<0,01)$ indicou ausência de associação.

Os resultados mostraram que elevadas produtividades estão associadas com um maior número de vagens por planta, número de grãos por vagem e número de lóculos por vagem, e com um menor tamanho de grão, mas a contribuição desses caracteres na produção de grãos é diferenciada, dependendo do local de cultivo.
Segundo Gonçalves et al. (2003), o número de vagens por planta e o número de grãos por vagem apresentam correlação positiva com o rendimento de grãos, enquanto que a massa de 100 grãos apresenta correlação negativa.

Considerando os efeitos diretos sobre a produtividade em Anchieta o número de grãos por vagem foi o caráter que possui o maior efeito e a maior correlação $(0,80)$, seguido da massa de 100 grãos $(0,43)$ e do número de vagens por planta $(0,13)$. O comprimento $(-0,14)$ e a espessura $(-0,16)$ da vagem apresentaram correlação negativa com a produtividade. 
Tabela 4 - Estimativa dos efeitos diretos e indiretos do caráter produtividade em feijoeiro e seus componentes do rendimento

\begin{tabular}{|c|c|c|c|}
\hline Caracteres & \multicolumn{3}{|c|}{ Estimativa da correlação } \\
\hline Número de vagens/planta & Anchieta & Joaçaba & Lages \\
\hline Efeito direto sobre produtividade & 0,13 & 0,23 & 0,61 \\
\hline Efeito indireto via número de grãos/vagem & 0,51 & $-0,20$ & 0,06 \\
\hline Efeito indireto via massa de 100 grãos & $-0,30$ & $-0,03$ & $-0,02$ \\
\hline Efeito indireto via comprimento da vagem & $-0,05$ & $-0,01$ & $-0,02$ \\
\hline Efeito indireto via espessura da vagem & 0,02 & $-0,04$ & $-0,04$ \\
\hline Número de lóculos/vagem & $<0,01$ & 0,47 & 0,07 \\
\hline Total & 0,42 & 0,40 & 0,68 \\
\hline \multicolumn{4}{|l|}{ Número de grãos/vagem } \\
\hline Efeito direto sobre produtividade & 0,80 & $-0,34$ & 0,14 \\
\hline Efeito indireto do número de vagens/planta & 0,08 & 0,14 & 0,27 \\
\hline Efeito indireto via massa de 100 grãos & $-0,29$ & $-0,03$ & $-0,02$ \\
\hline Efeito indireto via comprimento da vagem & 0,04 & $<0,01$ & $<0,01$ \\
\hline Efeito indireto via espessura da vagem & 0,04 & $-0,07$ & $-0,04$ \\
\hline Número de lóculos/vagem & $<0,01$ & 0,73 & 0,17 \\
\hline Total & 0,68 & 0,42 & 0,54 \\
\hline \multicolumn{4}{|l|}{ Massa de 100 grãos } \\
\hline Efeito direto sobre produtividade & 0,43 & 0,05 & 0,02 \\
\hline Efeito indireto do número de vagens/planta & $-0,09$ & $-0,15$ & $-0,39$ \\
\hline Efeito indireto via número de grãos/vagem & $-0,54$ & 0,23 & $-0,10$ \\
\hline Efeito indireto via comprimento da vagem & $-0,08$ & 0,03 & $<0,01$ \\
\hline Efeito indireto via espessura da vagem & $-0,04$ & 0,07 & 0,06 \\
\hline Número de lóculos/vagem & $<-0,01$ & $-0,56$ & $-0,13$ \\
\hline Total & $-0,33$ & $-0,33$ & $-0,53$ \\
\hline \multicolumn{4}{|l|}{ Comprimento da vagem } \\
\hline Efeito direto sobre produtividade & $-0,14$ & 0,57 & 0,06 \\
\hline Efeito indireto do número de vagens/planta & $-0,05$ & $-0,07$ & $-0,15$ \\
\hline Efeito indireto via número de grãos/vagem & $-0,21$ & $-0,01$ & 0,01 \\
\hline Efeito indireto via massa de 100 grãos & 0,24 & 0,02 & $<0,01$ \\
\hline Efeito indireto via espessura da vagem & 0,02 & $<0,01$ & 0,01 \\
\hline Número de lóculos/vagem & $<0,01$ & $-0,08$ & 0,06 \\
\hline Total & $-0,14$ & $-0,07$ & $<0,01$ \\
\hline \multicolumn{4}{|l|}{ Espessura da vagem } \\
\hline Efeito direto sobre produtividade & $-0,16$ & 0,16 & 0,09 \\
\hline Efeito indireto do número de vagens/planta & $-0,02$ & $-0,06$ & $-0,28$ \\
\hline Efeito indireto via número de grãos/vagem & $-0,21$ & 0,16 & $-0,06$ \\
\hline Efeito indireto via massa de 100 grãos & 0,11 & 0,02 & 0,02 \\
\hline Efeito indireto via comprimento da vagem & 0,01 & $<0,01$ & $<0,01$ \\
\hline Número de lóculos/vagem & $<-0,01$ & $-0,30$ & $-0,09$ \\
\hline Total & $-0,27$ & $-0,03$ & $-0,31$ \\
\hline
\end{tabular}


Continuação da Tabela 4

\begin{tabular}{lrrr}
\hline Número de lóculos/vagem & & & \\
Efeito direto sobre produtividade & $<0,01$ & 0,81 & 0,21 \\
Efeito indireto do número de vagens/planta & 0,08 & 0,13 & 0,21 \\
Efeito indireto via número de grãos/vagem & 0,65 & $-0,31$ & 0,12 \\
Efeito indireto via massa de 100 grãos & $-0,28$ & $-0,03$ & $-0,01$ \\
Efeito indireto via comprimento da vagem & 0,02 & $<-0,01$ & 0,02 \\
Efeito indireto via espessura da vagem & 0,06 & $-0,06$ & $-0,04$ \\
\hline \multicolumn{1}{c}{ Total } & 0,53 & 0,53 & 0,50 \\
\hline
\end{tabular}

Em Joaçaba, o número de lóculos por vagem $(0,81)$ foi o componente que apresentou o maior efeito, seguido do número de vagens por planta $(0,23)$. O comprimento $(0,06)$ e a espessura da vagem $(0,16)$ apresentaram correlação positiva, diferindo do resultado encontrado em Anchieta.

A correlação total do número de grãos por vagem com a produtividade em Joaçaba foi positiva, entretanto o efeito direto do número de grãos por vagem com a produtividade foi negativo $(-0,34)$. Tal fato é explicado pelo efeito indireto do número de grãos por vagem via número de lóculos ter apresentado coeficiente de correlação positivo e elevado $(0,73)$, o que justifica a correlação total positiva. Também pelo fato do efeito indireto da massa de 100 grãos via número de grãos por vagem ter sido positivo $(0,23)$, diferindo dos outros locais. Esses resultados evidenciam a complexidade do caráter produtividade e de que ele é o resultado da soma de todos os componentes do rendimento e não apenas o efeito isolado de um componente.

Em Lages, o número de vagens por planta $(0,61)$ apresentou o maior efeito e correlação com o rendimento de grãos, depois foi o número de lóculos por vagem $(0,21)$ e número de grãos por vagem $(0,14)$. O comprimento $(0,06)$ e espessura $(0,09)$ da vagem tiveram correlação positiva com a produtividade, apesar dos valores baixos. Em Lages e Joaçaba a massa de 100 grãos $(0,02$ e 0,05) apresentou correlação direta extremamente baixa, indicando uma ausência de associação direta entre esse caráter e a produtividade para os dois locais.

As respostas encontradas são um indicativo da necessidade das avaliações dos genótipos serem realizadas em diferentes ambientes, para o conhecimento de como determinado genótipo responde, principalmente quanto às características morfológicas e agronômicas, além de mostrar o efeito compensatório dos componentes do rendimento na produtividade final de grãos. Segundo Fageria et al. (2006), os componentes da produção não influenciam o rendimento final de grãos de forma independente, mas sim em conjunto. Em trabalho realizado com feijão-caupi (Vigna unguiculata), foi observada diferença no rendimento de grãos proveniente da alteração da população de plantas, apesar dos componentes, número de vagens por planta, número de grãos por vagem e massa de 100 grãos não terem apresentados diferenças (BEZERRA et al., 2007). No entanto, em pesquisa realizada com feijão, a cultivar Pérola apresentou maior produtividade que a cultivar Aporé, devido apresentar maior massa de 100 grãos e maior número de grãos por vagem, considerando-se distintas safras e condições de manejo nutricional das plantas; mas sendo considerado efeito principal na contribuição das diferenças o genótipo e a safra (TEIXEIRA et al., 2008).

Para os efeitos indiretos em Anchieta, o coeficiente de correlação da massa de 100 grãos principalmente via número de grãos por vagem evidenciaram valores negativos, o que implica uma correlação de caracteres em sentido contrário, onde o aumento de um corresponde a uma diminuição no outro. A seleção para elevar o número de vagens por planta e número de grãos por vagem via valor médio da massa do grão também apontou valores negativos para os coeficientes de correlação. Em trabalho realizado por Kurek et al. (2001), foram encontrados resultados semelhantes, onde o número de vagens por planta e número de grãos por vagem via valor médio da massa do grão também apresentaram correlação negativa. Contudo cabe ressaltar que o número de vagem por planta é dependente do número de nós na planta, seja no ramo principal ou de ramos laterais; embora o número de vagens por planta seja importante, ele é instável, com baixa herdabilidade e é influenciado por fatores morfológicos e fisiológicos relacionados ao crescimento e ao desenvolvimento da planta de Phaseolus vulgaris L. (CASQUERO et al., 2006) e Vigna unguiculata (MACHADO et al., 2008).

Porém, para os efeitos indiretos do número de vagens por planta e o número de lóculos por vagem 
principalmente via número de grãos por vagem mostram valores positivos, indicando que aumentos no número de vagens por planta e no número de lóculos tendem a aumentar o número de grãos por vagem e consequentemente a produtividade. Já os efeitos indiretos do número de grãos por vagem apresentam valores positivos muito pequenos. Portanto a seleção indireta a ser praticada entre o número de grãos por vagem não parece ser uma boa estratégia visando aumentos na produtividade.

Os efeitos indiretos do comprimento e espessura da vagem via número de grãos evidenciam valores de correlação negativos indicado que a seleção do comprimento e espessura da vagem via número de grãos para incrementos na produtividade não são eficientes. Já o efeito via massa de 100 grãos apresentaram correlações positivas, ou seja, a escolha do comprimento e espessura da vagem aumenta a produtividade via massa de 100 grãos.

Para os efeitos indiretos em Joaçaba, a correlação da massa de 100 grãos via número de vagens e número de lóculos por vagem apresentou valores negativos, porém via número de grãos por vagem os valores de correlação foram positivos. Isso indica que para esse local a escolha para elevar a massa de 100 grãos via número de vagens e número de lóculos não é uma boa estratégia, entretanto a seleção via número de grãos por vagem pode ser considerada um método eficiente.

Em Lages, para os efeitos indiretos, o coeficiente de correlação da massa de 100 grãos via número de grãos, número de vagens por planta e via número de lóculos por vagem foram negativos, onde o aumento de um corresponde a uma diminuição no outro. A opção para elevar o número de vagens por planta, número de grãos por vagem e número de lóculos por vagem via peso médio do grão também apontou valores negativos para os coeficientes de correlação. $\mathrm{O}$ efeito indireto do comprimento e espessura da vagem via número de vagens apresentou correlação negativa, o que indica uma correlação de caracteres em sentido contrário.

$\mathrm{O}$ efeito indireto do número de grãos em Lages via número de vagens e número de lóculos apresentaram correlação positiva. $\mathrm{O}$ efeito indireto do número de lóculos por vagem via número de vagens e número de grãos por vagens, também apresentou valores de correlação positivo, o que implica uma correlação de caracteres no mesmo sentido. Porém o efeito indireto do comprimento e espessura da vagem via número de vagens apresentou correlação negativa, o que indica uma correlação de caracteres sentido em sentido contrário.

No geral, a seleção indireta a ser praticada entre a massa de 100 grãos e o rendimento de grãos não parece ser uma boa estratégia para o progresso genético uma vez que, a maioria dos efeitos indiretos são negativos. Já no aspecto efeito direto sobre o rendimento, o número de vagens por planta, número de grãos por vagem, número de lóculos por vagem e massa de 100 grãos evidencia uma boa estratégia para incrementar este caráter complexo que é o rendimento de grãos.

\section{Conclusões}

1. Houve efeito de genótipo e local de cultivo para todos os caracteres avaliados e foram constatadas respostas diferenciadas dos genótipos ao ambiente de cultivo para todos os caracteres com exceção da massa de 100 grãos, mostrando a importância destes componentes no fenótipo do feijão, Phaseolus vulgaris;

2. O ambiente influenciou na intensidade com que os caracteres do rendimento explicaram a produtividade de grãos do feijão;

3. Entre os componentes do rendimento o maior número de vagens por planta, número de grãos por vagem e número de lóculos por vagem do feijoeiro contribuíram mais eficientemente na identificação dos genótipos mais promissores para rendimento de grãos.

\section{Agradecimentos}

Os autores agradecem a CAPES pela bolsa de mestrado do primeiro autor.

\section{Referências}

ANDRADE, F. N. et al. Estimativa de parâmetros genéticos em genótipos de feijão-caupi avaliados para feijão fresco. Revista Ciência Agronômica, v. 41, n. 02, p. 253-258, 2010.

BALKAYA, A.; ERGÜN, A. Diversity and use of pinto bean (Phaseolus vulgaris) populations from Samsun, Turkey. New Zealand Journal of Crop and Horticultural Science, v. 36, n. 03, p. 189-197, 2008.

BEZERRA, A. P. A. et al. Rendimento, componentes da produção e uso eficiente da terra nos consórcios sorgo x feijãode-corda e sorgo x milho. Revista Ciência Agronômica, v. 38, n. 01, p. 104-108, 2007.

CARBONELL, S. A. M. et al. Common bean cultivars and lines interactions with environments. Scientia Agrícola, v. 61, n. 02, p. 169-177, 2004.

CARBONELL, S. A. M. et al. Estabilidade de cultivares e linhagens de feijoeiro em diferentes ambientes no Estado de São Paulo. Bragantia, v. 66, n. 02, p. 193-201, 2007. 
CASQUERO, P. A. et al. Performance of common bean (Phaseolus vulgaris L.) landraces from Spain in the Atlantic and Mediterranean environments. Genetic Resources and Crop Evolution, v. 53, n. 05, p. 1021-1032, 2006.

COELHO, C. M. M. et al. Diversidade genética em acessos de feijão (Phaseolus vulgaris L.). Ciência Rural, v. 37, n. 05, p. 1241-1247, 2007.

COMISSÃO DE QUÍMICA E FERTILIDADE DO SOLO RS/SC (CQFS-RS/SC) Manual de adubação e de calagem para os estados do Rio Grande do Sul e Santa Catarina. 10. ed. Porto Alegre: SBCS - Núcleo Regional Sul/UFRGS, 2004. $400 \mathrm{p}$.

COSTA, J. C. G.; ZIMMERMANN, M. J. O. Melhoramento genético. In: ZIMMERMANN, M. J. O.; ROCHA, M.; YAMADA, T. (Ed.). A cultura do feijoeiro: fatores que afetam a produtividade. Piracicaba: Potafós . 1988. p. 229-245.

CRUZ, C. D.; REGAZZI, A. J. Modelos biométricos aplicados ao melhoramento genético. Viçosa: UFV, 1994. 390 p.

ELIAS, H. T. et al. Variabilidade genética em germoplasma tradicional em feijão preto em Santa Catarina. Pesquisa Agropecuária Brasileira, v. 42, n. 10, p. 1443-1449, 2007.

EPAGRI. Atlas climatológico do estado de Santa Catarina. Disponível em: http://ciram.epagri.rct-sc.br. Acesso em: 26 jul. 2010 .

FAGERIA, N. K.; BALIGAR, V. C.; CLARK, R. B. Physiology of crop production. New York: Food Products Press, 2006. 345 p.

GONÇALVES, M. C. et al. Correlations and path analysis of common bean grain yield and its primary components. Crop Breeding and Applied Biotechnology, v. 3, n. 03, p. $217-$ 222, 2003.

IBGE. Levantamento Sistemático da Produção Agrícola. Rio de Janeiro v. 21 n. 12. 2009. Online. Disponível em: $<$ ftp://ftp.ibge.gov.br/Producao_Agricola/Levantamento_ Sistematico_da_Producao_Agricola_[mensal]/Fasciculo $>$. Acesso em: 05 mai. 2010.

IPGRI. Descritores para Phaseolus vulgaris L. Rome: International plant genetic resources institute, 2001. 45 p.

KAPPES, C. et al. Feijão comum: características morfoagronômicas de cultivares. In: CONGRESSO NACIONAL DE PESQUISA DE FEIJÃO, 9., Campinas. Anais... Campinas: IAC, 2008. p. 506-509.
KUREK, A. J. et al. Análise de trilha como critério de seleção indireta para rendimento de grãos em feijão. Revista Brasileira de Agrociência, v. 7 n. 01, p. 29-32, 2001.

LEMOS, L. B. et al. Características agronômicas e tecnológicas de genótipos de feijão do grupo comercial Carioca. Pesquisa Agropecuária Brasileira, v. 39, n. 04, p. 319-326, 2004.

LITTEL, R. C. et al. SAS $\AA^{\circledR}$ for Mixed Models. 2. ed. SAS Institute Inc.: Cary, NC, USA. 2006. 834 p.

LITTEL, R. C.; FREUND, R. J.; SPECTOR, P. C. SAS System for linear models. 3. ed. SAS Institute Inc.: Cary, NC, USA. 1991.329 p.

MACHADO, C. F. et al. Identificação de genótipos de feijão-caupi quanto à precocidade, arquitetura da planta e produtividade de grãos. Revista Ciência Agronômica, v. 39, n. 01, p. 114-123, 2008.

MWALE, V. M. et al. Yield performance of dwarf bean (Phaseolus vulgaris L.) lines under Researcher Designed Farmer Managed (RDFM) system in three bean agro-ecological zones of Malawi. African Journal of Biotechnology, v. 07, n. 16, p. 2847-2853, 2008.

RAMALHO, M. A. P.; SANTOS, J. B., ZIMMERMANN, M. J. de O. Genética quantitativa de plantas autógamas: aplicações ao melhoramento do feijoeiro. Goiânia: UFG, 1993. 271 p.

RAMOS JUNIOR, E. U.; LEMOS, L. B.; SILVA, T. R. B. Componentes da produção, produtividade de grãos e características tecnológicas de cultivares de feijão. Bragantia, v. 64 , n. 01, p. $75-82,2005$.

RIBEIRO, N. D. et al. Estabilidade de produção de cultivares de feijão de diferentes grupos comerciais no estado do Rio Grande do Sul. Bragantia, v. 68, n. 02, p. 339-346, 2009.

SCOTT, A. J.; KNOTT, M. A cluster analysis method for grouping means in the analysis of variance. Biometrics, v. 30, n. 03, p. 507-512, 1974.

SHIMADA, M. M.; A R F, O.; SÁ, M. E. Componentes do rendimento e desenvolvimento do feijoeiro de porte ereto sob diferentes densidades populacionais. Bragantia, v. 59, n. 02, p. 181-187, 2000.

STEEL, R. G. D.; TORRIE, J. H.; DICKEY, D. A. Principles and procedures of statistics a biomerical approach. 3. ed. McGraw-Hill: New York, USA. 1997. 666 p.

TEIXEIRA, I. R. et al. Fontes de silício em cultivares de feijão nas safras das águas e da seca. Revista Ciência Agronômica, v. 39 , n. 04, p. $562-568,2008$. 